\title{
The Effect of Self-Regulation of Shame on Teenagers' Aggression
}

\author{
Liusheng Wang1, Biao Sang ${ }^{2}$ \\ ${ }^{1}$ Department of Psychology, Nantong University, 9 Seyuan Road, Nantong, Jiangsu, People's Republic of China \\ 2 School of Psychology and Cognitive Science, East China Normal University, 3663 N. Zhongshan Road, Shanghai, \\ People's Republic of China
}

\begin{abstract}
Studies have found that shame and aggression are closely connected, and self-blaming and re-planning strategies can regulate an individual's shame. This study conducted two experiments to investigate the effects of self-regulation of shame on explicit and implicit aggressiveness of adolescents. Shame was induced in both experiments by audio recordings describing different shameful situations that adolescents may experience in daily life. The participants of $7^{\text {th }}$ grade were required to self-regulate their shame by self-blaming strategy, re-planning strategy, or non-regulation, and rated their explicit aggressiveness in Study 1 and did implicit association test (IAT) in Study 2, respectively. The current studies found that the regulation of shame with self-blaming strategy enhanced explicit aggression, but did not affect the bias of implicit aggression.
\end{abstract}

Key words: shame, aggression, emotional regulation, implicit association tests

\section{Introduction}

Shame is a painful experience that involves a negative evaluation of one's entire self. This evaluation and self-censorship changes an individual's self-perception, and is accompanied by feelings of fright, and a sense of insignificance, powerlessness, and worthlessness, as well as public exposure (Lewis, 1971). As a negative self-consciousness emotion, shame has a detrimental effect on an individual's psychology and behavior, such as enhanced aggression.

\section{Shame and Aggression}

There have been theories and empirical studies that focused on the relationship between shame and aggression (Elison, Garofalo, \& Velotti, 2014). The Compass of Shame proposed by Nathanson focuses on the role of individual shame in the self (Nathanson, 1992). Attacking others is one of the four typical ways that individuals deal with shame. Individuals are often unwilling to accept shame when they experience it, so they externalize shame by directing anger at others or the external environment, which in some way enables selves to feel the diminished shame.

Sinha's shame-anger theory proposed that shame is accompanied by intense hostility and anger (Sinha, 2017). Similarly, Harper and Arias proposed that shame may lead to anger and hostility, and finally to aggression and other defensive behaviors (Harper \& Arias, 2004). Shame has a protective motive. When shame activates protective motivation and the indi-

Correspondence concerning this article should be addressed to Liusheng Wang, Department of Psychology, Nantong University, 9 Seyuan Road, Nantong, Jiangsu, P. R. China. E-mail: willow76@ntu.edu.cn ORCID https://orcid.org/0000-0001-7899-0081

The data that support the findings of this study are available from the corresponding author, upon reasonable request.

Received May 8, 2019

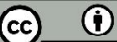


vidual protects him/herself, this leads to aggression (de Hooge, Breugelmans, Wagemans, \& Zeelenberg, 2018; de Hooge, Zeelenberg, \& Breugelmans, 2010), and demonstrates the destruction function of shame. Experiencing shame early in life can increase the risk of psychological problems (Heaven, Ciarrochi, \& Leeson, 2009; Tangney, 1992). Individuals faced with rejection and humiliation continually seek to condemn the scapegoat who caused them pain. The shame-anger spiral theory explains the interactive, spiraling relationship between shame and anger (Scheff, 2012). This theory proposes that when an individual perceives his or her own shame, this induces anger, which further induces stronger shame in a cycle of "shame-angershame". Some clinical psychological disorders, such as post-traumatic stress disorder and social phobia, are thought to reflect the effects of this cycle (Dai, Wang, \& Qian, 2012). Unbearable shame eventually may lead to extreme violence and even war at the societal level (Scheff, 2014). The spiral theory can be described in a popular way as follows. As emotions grow and gather strength with the passage of time, individuals are ashamed because they have already experienced shame; they are angry because they are ashamed; and they are ashamed because of their anger. The cycle continues back and forth, accumulating more and more power over time until anger, depression, attack or self-inflicted harm is triggered.

According to the "social pain and threat" model proposed by Elison and his colleagues (Elison, Garofalo, \& Velotti, 2014), shame is considered to be social pain. The relationship between shame and aggressiveness is similar to the relationship between physiological pain and aggressiveness. Shame is an adaptation to threats, similar to the way bodily pain is a defense against general physical threats of injury. The model's basic path is that threats to personal reputation, social rank, or relationships generate shame, then physical pain, and finally anger and aggression. Rage and aggression may be viewed as an evolutionary adaptive coping mechanism, a psychological defense, or emotional regulation. Two arguments support the model's postulated path. First, social exclusion causes physical pain (Eisenberger, 2011). An fMRI study by Eisenberger et al. showed that activity in the anterior cingulate cortex exhibits similar patterns in response to social rejection and bodily pain (Eisenberger, Lieberman, \& Williams, 2003). Second, physical pain can produce anger and attack (Berkowitz, 2012).

Many empirical studies support the relationship between shame and aggressiveness from different perspectives. Shame is positively correlated with juvenile delinquency (Gold, Sullivan, \& Lewis, 2011), aggressive behavior (Stuewig \& Tangney, 2007; Stuewig et al., 2015), and hostility (Elison et al., 2014; Velottin, Garofalo, Bottazzi, \& Caretti, 2016). An eightyear longitudinal study found that early shameprone children in Grade 5 experienced more destructive behaviors, such as drug abuse, detention, imprisonment, and suicide in later life (Tangney, 1992). A short-term longitudinal study found that shame and hostility were highly stable during a one-year period, and that high levels of shame among 9th grade students was a good predictor of increased hostility in the 10th grade (Heaven et al., 2009). Moreover, one study found juvenile offenders, who were less empathetic, experienced less shame (Schalkwijk, Stams, Stegge, Dekker, \& Peen, 2016).

The relationship between shame and aggression may be influenced by other factors. Event awareness moderates the effect of shame on anger at others, and shame can even decrease an individual's anger about the unfairness of others, when the others are aware of the individual's experience of shameful events (Zhu et al., 2019). An adolescent's social status can affect the risk of aggressive behavior when experiencing shame; for instance, moderate social status has a protective function on the relationship between shame and aggression (Åslund, Leppert, Starrin, \& Nilsson, 2009). Blame is another factor that influences the relationship between shame and aggression. For example, Stuewig et al. found that externalization of blame medi- 
ated the association between shame and aggression in college students, adolescents, and adult prisoners (Stuewig, Tangney, Heigel, Harty, \& McCloskey, 2010). Shame can also affect aggression indirectly through coping strategies, such as self-blaming, blaming others, and escaping (Zhang, Zhang, \& Huang, 2013). In addition, the mechanism underlying the association between shame and aggression differs by gender (Scheff \& Retzinger, 1997), with females having a shame-shame feedback mechanism and males having a shame-anger feedback loop.

\section{Shame Regulation}

As one of the self-conscious emotions, shame can be regulated by different strategies, some of which are as effective as well-established techniques for regulating the basic emotions. The shame-resilience theory attempts to explain how individuals recover from shameful events by using certain strategies (Van Vliet, 2008). For example, research has shown that self-compassion and cognitive reappraisal can significantly reduce shame-proneness, and that symptoms of social anxiety can also be significantly reduced by self-compassion (Cándea \& Szentágotai-Tătar, 2018). Other studies have found that shame among middle-school students is positively correlated with self-blaming (Fan \& Yu, 2008), and that self-blaming, blaming-others, and evading strategies mediate the relationship between shame and aggression (Zhang et al., 2013). Gao conducted a series of survey studies of the shame regulation of college students. The studies found that negative cognitive assessments of college students mainly entailed shame (Gao, Zhao, Wang, Dai, \& Qian, 2012). The regulation strategies of shame can be classified into four sub-categories, including a repair strategy (e.g., self-change strategy and re-evaluation strategy), and a defensive strategy (e.g., denial-attack strategy and avoidanceretreat strategy) (Gao et al., 2012). Compared to the regulatory strategies of general negative emotions, the undergraduate students were more likely to use a catastrophic strategy in which they focused on the catastrophic consequences, and they were less likely to regulate shame by such strategies as acceptance, "putting things in perspective", rumination, positive reappraisal, and positive refocusing (Gao, Qian, \& Wang, 2011).

The re-planning and "putting into perspective" strategies are relatively effective for regulating shame, whereas the self-blaming and blaming-others strategies are relatively ineffective. The re-planning strategy can help individuals to engage in constructive and compensatory behavior (Gao, 2016). Wang and Sang found that re-planning and self-blaming strategies enhanced adolescent's intensity of shame, with medium effect sizes of regulation (Wang \& Sang, 2019).

\section{Situations of Shame}

Being different from children whose life is mainly inside of family, teenagers stay longer hours in schools, and interact with peers and teachers. Their life situations mainly involve activities on campus, such as learning activities or playing. Autonomy becomes an important theme of teenagers' development, including behavior, emotion and value autonomy (Steinberg, 2017). Teenagers begin to have more opportunities to govern their own behavior, and spend more time outside of direct supervision by their parents. The social domain theory based domain specificity model proposes that individuals have different types of social interactions and that their varied interactions lead to the development of different types, or domains, of social knowledge (Smetana, 2002; Smetana, Crean, \& Campione-Barr, 2005). Greater domain specificity will add precision to the assessment of the development and contribute to the understanding of shame emotion. Social domains for teenagers mean different situations. Schools, as social institutions, have a responsibility to nurture and guide teenagers; however, schools often perpetuate the cycle of shame (Monroe, 2008). Or, schools could carry on the intervention of shame (Hunger \& Böhlke, 2018). Therefore, teenagers have autonomy 
to deal with different negative life events, involving the inside or outside of school situations, and to regulate negative emotion, such as shame. It is necessary to focus on teenagers' shame in two different social domains, which are divided into situations inside and outside of schools.

\section{The Current Study}

As shame can affect aggression and individuals can regulate shame using various strategies, one issue of importance arises about how specific types of self-regulation of shame affect an individual's aggression.

Incidents involving shame are closely related to an individual's situation, and the major life events of adolescents revolve around school and learning. Thus, incidents of shame among adolescents are likely to occur in the unique context of school, namely, being called as domain specificity, such as splash and squelch eating in the school dining hall, examination cheating, poor learning performance, and other shameful events that can happen on campus; we call these unique situations. Other shameful events can occur that are not related to school, such as littering in public places, unpleasant body odor, and family conflicts; we call these general situations. This study examined the effect of shameful events on adolescents in these two types of situations.

There are many types of emotional regulation strategies. Re-planning and self-blaming are common strategies in the daily life of a teenager (Wang, 2017), and they can independently affect the intensity of an individual's shame (Wang \& Sang, 2019). Based on Gross' process model of emotion regulation (Gross, 2015; Gross \& Thompson, 2007), emotion regulation is divided into antecedent-focused and response-focused regulation (Gross, 1998). Specifically, more attention is paid to two strategies named cognitive reappraisal and expressive suppression. Generally, increased use of cognitive reappraisal predicts increased levels of positive well-being outcomes (Haga, Kraft, \& Corby, 2009). Cognitive reappraisal can be serviced for different emotion goals, with different tactics (McRae, Ciesielski, \& Gross, 2012). The re-planning strategy is an antecedent-focused, and it is a cognitive reappraisal strategy that emphasizes regulation before an emotional response occurs and ways individuals can regulate emotions by avoiding shameful events. The re-planning strategy is a repair-type strategy that involves active measures to repair self-injury, which is a relatively positive cognitive-regulation strategy, similar to the refocusing strategy of the shame-resilience theory. In the current research, re-planning is a re-imagination of the presented hypothetical scenario. These scenarios were designed to select from a pool of scenarios and rated by teenagers in the pilot study. So, these scenarios often happen in teenagers' life, are not far removed from teenagers' life. They are common life events for teenagers, and easy to understand by them. These scenarios are not strange to them. Additionally, there is research that has provided some support for re-planning strategy use to regulate emotion. Originally, emotional regulation primarily aims to regulate the negative emotions, using different strategies. In the Cognitive Emotion Regulation Questionnaire (CERQ), developed by Garnefski and his colleagues, re-planning is one of the cognitive reappraisal strategies in emotion regulation, and is theoretically more adaptive (Garnefski \& Kraaij, 2007). Cognitive reappraisal can be serviced for different emotion goals, using different tactics (McRae et al., 2012). Generally, increased use of cognitive reappraisal could predict increased levels of positive well-being outcomes (Haga et al., 2009). Regarding shame regulation, Gao (2016) found that the re-planning strategy is relatively effective for regulating shame. Wang and Sang (2019) found that the re-planning strategy could affect adolescent's intensity of shame. Therefore, replanning is a relevant strategy in hypothetical situations, and often taken as a strategy in shame and other negative emotions regulation.

The self-blaming strategy, on the other hand, is a response-focused emotion regulation, and 
it is repressive coping rather than expressive suppressing. Expressive suppressing refers to the process of consciously inhibiting emotional expressions while emotionally aroused (Gross, 2002; Gross \& Levenson, 1993). The term repressive orientation is synonymous with the term defensive. Repressive coping is a strategy of self-protection that involves dismissing or ignoring emotions one feels. In situating negative context, individuals with repressive coping often report little distress, while simultaneously presenting threat reactivity through other response channels, ultimately protecting themselves, or preserving a selfimage. In nature, repressive coping may serve a protective function (Coifman, Bonanno, Ray, \& Gross, 2007). The self-blaming strategy addresses the self-attributions about shameful events to achieve shame regulation. It is a relatively passive regulation strategy that is essentially defensive and corresponds to the attackself script in the "compass of shame" model (Elison, Lennon, \& Pulos, 2006). Taking into account the significance and operation of different strategies, this study used the re-planning strategy and the self-blaming strategy as individual self-regulation strategies in Experiment 1.

Not only are individuals directly or explicitly aware of their own aggressive experiences, they may have an implicit experience of aggression (Dai, Yang, \& Wu, 2005). And, inducing shame could affect an individual's implicit moral self (Zhou, 2015). Therefore, this study conducted two experiments to examine the effect of shame regulation on subsequent explicit aggression towards others and the bias of implicit aggression. The purpose of Experiment 1 was to examine the effect of shame regulation on explicit aggression using a repeated-measures experimental design. Considering the role of regulation strategies and the motives of shame, the experimental hypothesis was that there would be a significant difference in explicit aggression between the self-regulation conditions and the non-regulation condition; that is, a self-regulation strategy should strengthen the explicit aggressiveness towards others. Experiment 2 examined whether shame regulation using the self-blaming strategy would affect the bias of implicit aggression.

\section{Study 1}

Study 1 was designed to examine the effect of shame after regulation by different strategies on explicit aggression. As the intensity of the induced shame in the study was medium level, and the immediate self-assessments can enhance the influence of the current emotional experience on subsequent behavior, the study used a repeated-measures experimental design.

The regulatory strategies used in the experimental procedure were expressed in specific and clear instructions to ensure the adolescents participating in the experiment understood them (Wang \& Sang, 2019): 1) Self-blaming was expressed as, "I blame myself". For example, "I should be blamed"; "I should take responsibility for what happened"; "In this case, I was wrong"; and "I was the main reason for this fault"; 2) Re-planning was expressed as, "I managed to do it better". For example, "I think about how to do it better"; "I think how best to deal with these situations"; "I think how to change this situation"; and "I want a better plan to do it". 3) Non-regulation means the participants did not do anything; they just looked at the computer screen. The participants were instructed to imagine or meditate on the specific method when the computer prompted the use of a strategy. The non-regulation condition was used as a baseline in the repeated-measures design, which facilitated the comparison of the selfblaming and re-planning strategies.

\section{Methods}

\section{Participants}

Ninety-one students in Grade 7 participated in the experiment. The data of 87 students were included after data screening. Mean age $=13.52$ years, $S D=0.80,42$ students were male. 


\section{Materials}

Stories were used to induce shame. The materials were adopted from studies by Wang (2017) and Wang and Sang (2019). The stories about shame were created based on interviews and open-ended survey questions. Six stories were chosen for use in this study based on shame ratings made by 500 students from Grades 7 to 11. These stories included unique situations, such as chewing loudly in the school dining-hall, cheating on an examination, and poor school performance, and general situations, such as littering, having body odor, and family conflict. Three similar stories were created to meet the requirements of the repeated-measures design.

Thirty-eight postgraduate students $(28 \mathrm{fe}$ males; Mean age $=20.50$ years, $S D=1.41$ ) were asked to rate the similarity of the three stories on a 7-point scale. Higher ratings indicated greater similarity. The results showed that the similarity ratings of the three stories were above 5 points. The results of one-sample $t$-test, using point 4 (the midpoint of the Likert 7-point scale) as the reference value, revealed the mean was significantly different from 4 , chewing noise, $t(37)=5.99$, Cohen's $d=0.98$; cheating on exam, $t(37)=10.30$, Cohen's $d=1.67$; poor performance, $t(37)=7.69$, Cohen's $d=1.24$; littering, $t(37)=11.13$, Cohen's $d=1.81$; body odor, $t(37)=9.56$, Cohen's $d=1.54$; family conflict, $t(37)=9.52$, Cohen's $d=1.53$; $p s<0.001$. The stories were also rated for the intensity of the shame or guilt experienced by the story's protagonist. Higher ratings indicated that the strength of emotion experienced by the protagonist was greater. A paired-sample $t$-test showed that the shame ratings of all the story situations were significantly higher than the guilt ratings were (see Table 1).

The texts of the stories were read by a radio hostess, and recorded in MP3 format. The mean duration of the audio files was 40.56 $(S D=5.93)$ seconds. A postgraduate student in the art department drew pencil sketches based on the core content and core elements of each story's situation. These sketches were converted to electronic files in the JPG format, with $640 \times 470$ pixels.

Six neutral images were selected from the International Affective Picture System (IAPS) for use during relaxation portions of the experiment. The valence of the neutral images was $M=4.97(S D=0.12)$; the arousal score was $M=2.52(S D=0.42)$. Eight college students were asked to rate the degree to which soft music was soothing on a 7-point scale. The mean rating of the piece, which was from "Dancing with the Neon Light" (www.ximalaya.com) was 1.38 , which indicated portions of the music were soothing.

The measure of explicit aggressiveness was based on Buss's definition. According to Buss's general structure and definition of aggression (Buss \& Perry, 1992), aggression generally includes physical attacks, verbal attacks, anger, and hostility, designed to mea-

Table 1 Ratings of shame and guilt

\begin{tabular}{|c|c|c|c|c|c|c|c|}
\hline \multirow{2}{*}{ Situations } & \multicolumn{3}{|c|}{ Shame } & \multicolumn{2}{|c|}{ Guilty } & \multirow[b]{2}{*}{$t$} & \multirow[b]{2}{*}{ Cohen's d } \\
\hline & Stories & $M$ & $S D$ & $M$ & $S D$ & & \\
\hline \multirow[t]{3}{*}{ Unique } & chewing noise & 5.37 & 1.13 & 3.08 & 2.31 & $5.64^{* * *}$ & 0.91 \\
\hline & cheating on exam & 5.66 & 1.12 & 3.24 & 2.35 & $5.34^{* * *}$ & 1.01 \\
\hline & poor performance & 5.37 & 1.32 & 3.03 & 2.18 & $5.15^{\star * *}$ & 1.33 \\
\hline \multirow[t]{3}{*}{ General } & littering & 5.50 & 0.95 & 3.37 & 2.40 & $5.41^{* * *}$ & 0.88 \\
\hline & body odor & 5.71 & 1.29 & 3.11 & 2.20 & $5.81^{* * *}$ & 1.12 \\
\hline & family conflict & 5.26 & 1.01 & 3.29 & 2.37 & $4.75^{\star * *}$ & 0.77 \\
\hline
\end{tabular}

${ }^{* * *} p<0.001$ 
sure the aggression to others. Physical and verbal attacks are forms of behavior, anger is an emotion, and hostility entails cognition (Liu, Zhou, \& Gu, 2009). This experiment used descriptions from the revised Chinese version of the "Buss-Perry Aggression Questionnaire" for use with adolescents (Buss \& Perry, 1992; Liu et al., 2009; Zhou, 2007). Six items from the anger and the hostility sub-scales were selected for use, in accordance with the purpose of the study: for example, "I can't control my temper" (anger); and "I think others always have good luck" (hostility).

\section{Procedures}

The experiment consisted of two consecutive stages: an inducing-regulation stage and an explicit-aggression measurement stage. Before the experiment, all the participants completed a practice session and indicated they understood the regulation-strategy manipulation. All the stories were presented in three blocks during the experiment by the E-prime software program. The order of the blocks was randomized, and the order of the story situations within the blocks was balanced. Each block used only one kind of regulation strategy. The blocks were separated by an interval of 120 seconds, during which time the participants listened to relaxing music. Subsequently, for 3 minutes the rest of the blocks were presented.

Each trial consisted of the following five steps (Deng, Sang, \& Ruan, 2013; Gao et al., 2012).
Step 1 - Fixation. The center of the screen displayed an up arrow, a down arrow, or a short horizontal line for $2 \mathrm{~s}$, indicating the participants should regulate their shame with the corresponding regulation strategy. Step $2-$ Inducement. The screen presented a picture, while the participants, wearing headsets, listened to the description of the situation corresponding to the picture. The participants were instructed to imagine themselves as the protagonists in the situations in the stories and to experience the shameful emotions fully. After the audio recording ended, the picture disappeared; the average audio duration was about 41 s. Step 3 - Regulation. A symbol was presented on the screen that represented the regulation strategy; only one type of regulation strategy was used in each block. The strategies comprised the re-planning strategy, the self-blaming strategy, and the non-regulation strategy. The screen displayed the following instructions: " $\downarrow$ " stands for "I managed to do better"; "^" stands for "I blame myself"; and "-" stands for "non-regulation". Participants regulated themselves in accordance with the instructions given before the experiment. The duration of the display was $5 \mathrm{~s}$. Step 4 - Rating explicit aggression. Participants rated themselves according to the description of aggression on the screen by pressing the numbered computer keys on 4-point scale. Step 5 - Relaxation. The screen showed a neutral affective picture, while the participants listened to relaxing music through the headset. There were 18 trials total for every participant.

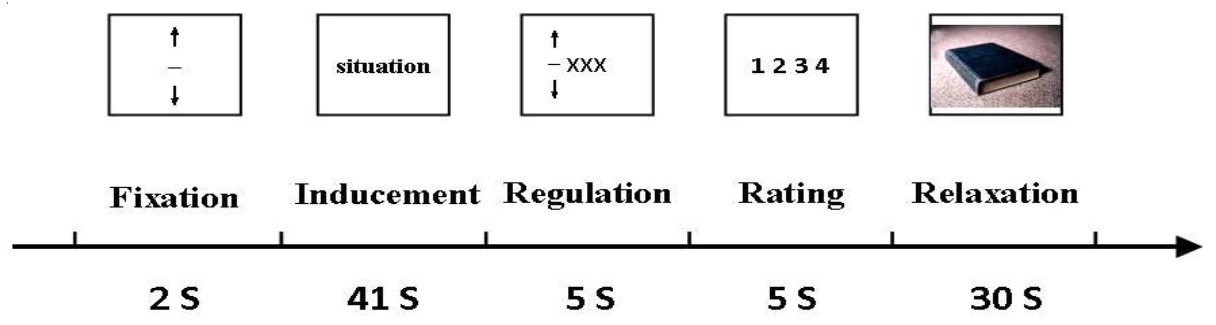

Figure 1 Procedures for emotional regulation 


\section{Results}

The reaction time of the participants was recorded while they rated explicit aggression in Step 4. The reaction time data were retained for analysis based on the following criteria: the reaction time was more than $300 \mathrm{~ms}$ and less than $20,000 \mathrm{~ms}$, and the data for all the three regulation strategies were complete (i.e., no missing data in one of the regulation strategies).

A repeated-measures ANOVA was conducted on the ratings of explicit aggression in the unique situations, with regulation strategies and gender as independent variables. The ANOVA found a significant main effect of the regulation strategies, $F(2,464)=3.54, p<0.05$, $\eta^{2}=0.02$, indicating that the regulation strategies affected the self-ratings of aggression. Post-hoc tests showed that aggression ratings after the self-blaming strategy were significantly higher than the ratings in the re-planning strategy and non-regulation conditions ( $p s<0.05$ ). The main effect of gender was not significant, and the interaction of regulation strategy with gender was not significant ( $p s$ > 0.05; see Table 2).

The repeated-measures ANOVA on the aggression ratings in the general situations showed no significant main effect of the regulation strategies, $F(2,235)=2.63, p>0.05$. The main effect of gender was not significant, and the interaction of regulation strategy and gender was not significant ( $p s>0.05)$.

\section{Discussion}

A significant regulation effect of the self-blaming strategy in unique situations was found, whereas no effect of any regulation strategies was present in general situations, indicating an enhanced effect of regulation with self-blaming strategy on explicit aggressiveness in the specific circumstances.

The experimental results are consistent with existing research findings. Previous studies on the relationship between shame and aggression have found that shameful experiences can increase adolescent hostility (Heaven et al., 2009), that shameful experiences are strongly related to aggressive behavior (Åslund et al., 2009), and that shame can lead to more aggressive behavior (Schoenleber, Sippel, Jakupcak, \& Tull, 2015). Moreover, self-blaming strategy has been found to be a partial mediator of the association between shame and aggression (Zhang et al., 2013).

Attacking others is one of the typical responses to shame in Nathanson's "Compass of Shame" model (Nathanson, 1992). Attacking others is accompanied by self-loathing and anger, which involves the relationship between the individual self and others. Self-blaming strategy corresponds to aggressive-reaction script in the "Compass of Shame" model (Elison et al., 2006). The self-blaming strategy is similar to self-compassion in the self-direction strategy, which can reduce shame-proneness (Cándea \& Szentágotai-Tătar, 2018). However, these two strategies stand in different perspectives concerning the responsibility of the self. Self-blaming strategy places more responsibility on the individual, whereas self-compassion supports the individual with understanding and sympathy. Therefore, selfblaming would produce different outcomes regarding shame than those produced by selfcompassion.

Table 2 Aggression after regulation in the unique and general situations

\begin{tabular}{lcccccc} 
Regulation & \multicolumn{3}{c}{ Unique situations } & \multicolumn{3}{c}{ General situations } \\
Strategies & $M$ & $S D$ & $F$ & $M$ & $S D$ & $F$ \\
\hline Non-regulation & 2.03 & 0.95 & $3.54^{*}$ & 2.13 & 0.96 & 2.63 \\
Re-planning & 2.05 & 1.00 & & 2.24 & 1.00 & \\
Self-blaming & 2.20 & 1.03 & & 2.27 & 1.09 & \\
\hline
\end{tabular}

${ }^{*} p<0.05$ 
In the unique context of shame (e.g., examination cheating or poor performance), in which adolescents' experiences are closely related to school, adopting the self-blaming strategy to regulate shame corresponds to aggression in the "Compass of Shame" model. Self-blaming strategy provides clues to the reaction as part of the aggressive dimension of shame. The dual roles of self-blaming and typical responses to shame by "Compass of Shame" model are superimposed, leading to explicit aggressiveness by adolescents. The re-planning strategy focuses on regulation before a shameful incident occurs, so it is merely a hypothetical operation. Individuals who are already in a shameful situation, feel helpless and experience negative feelings, but this is not enough to trigger aggression.

The experiment also found that the effectiveness of strategies changed with the type of situation, and that the regulatory effect in unique situations involving school or learning was more pronounced. Generally, the induction of shame is closely related to the nature of the events. The unique context in this experiment refers to the close relationship between the "personal lives" and the "school lives" of students. Adolescents have more autonomy and can take initiative in unique situations, and they bear more responsibility for the consequences of shameful incidents. Therefore, the regulatory effect of the self-blaming strategy in a unique situation is stronger than that in a general situation.

\section{Study 2}

The results of Experiment 1 showed that the self-blaming strategy can enhance an individual's explicit aggression after regulating shame. However, when a person is not aware of his offensiveness, the person may still be angry at others and become implicitly aggressive. Thus, the research question arises: As there exists the effect of regulation with selfblaming strategy on shame, does this strategy affect an individual's bias of implicit aggression? Study 2 was designed to answer that question. Study 2 used a single-factor re- peated-measures design, which was similar to Study 1 . However, only the self-blaming strategy and non-regulation conditions were examined, with the latter used as the baseline or control condition. The dependent variable implicit aggression was measured using the implicit association test (IAT) paradigm.

\section{Methods}

\section{Participants}

Ninety-five students in Grade 7 were assigned to the self-blaming strategy group and the nonregulation group. The students were different from the sample in Study 1. The data of 15 students were excluded from the analyses because their correct ratio, which referred to the corrected reaction in IAT experiment, was $<0.8$ or because of misconduct during the experiment. The remaining participants were 80 students, 32 males, Mean age $=14.27(S D=0.63)$.

\section{Materials}

The story situation "examination cheating" in Study 1 was selected as the shame-inducing situation in Study 2. The emotional regulation materials were the same as those used in the self-blaming strategy condition and non-regulation condition in Study 1.

The IAT materials were adopted directly from the previous implicit aggression studies (Xie, $\mathrm{Bi}$, \& Luo, 2010; Yang, 2012). The self-concept dimension included 5 words in self dimension and 5 in the others dimension. The associated attribute dimension of aggression included 5 aggressive adjectives and 5 non-aggressive adjectives (see Table 3 ).

\section{Procedures}

The experiment consisted of the inductionregulation phase and the IAT phase. Classical music was broadcast by earphones before and after the experiment in order to ease the relaxation of the participants. The induction-regulation phase was the same as that in Study 1. 
The IAT phase was conducted with an IAT program that had 7 steps (Greenwald, Nosek, \& Banaji, 2003), including 5 practice tasks and 2 test tasks (see Table 4). Step 1 was practice to identify the target concept words as quickly and correctly as possible, classify the words belonging to the concept "self" and press the "D" key to respond, and to classify the words belonging to the concept "others" and press the "K" key to respond. Step 2 was practice to distinguish the attribute concept words as quickly and correctly as possible, classify the words belonging to the concept "attack" and press the "D" key to respond, and to classify the words belonging to the concept "non-attack" and press the "K" key to respond. Step 3 was practice to jointly identify all the stimulus words presented in the first two steps, categorize the words belonging to the concepts "self" and "attack" and press the "D" key to respond, and to identify the words belonging to the concepts of "others" and "non-attack" and press the "K" key to respond. Step 4 was the same as Step 3, but the fourth step was the formal test phase, and the reaction times and correct rates were recorded. Step 5 was the opposite of the target-concept discrimination exercise. Contrary to Step 1, the participants identified words belonging to the concept "others" and press the "D" key to respond, and identified words belonging to the concept "self" and press the "K" key to respond. Step 6 was practice on the incompatibility joint-task identification. The "others" and "attack" words had to be classified and the "D" key used to respond, and the "self" and "non-attack" words had to be classified and the "K" key used to respond. Step 7 was the same as Step 6. Step 7 formally tested reaction times and correct rates.

\section{Results}

The data underwent a preliminary analysis in accordance with Greenwald's rules (2003). Participants were eliminated if their correct ratio was below 0.8 . The reaction times were re-

Table 3 IAT materials

\begin{tabular}{|c|c|}
\hline Type & Words \\
\hline Self & I(Wo), Myself(ZiJi), Me(BenRen), Me(An), We(WoMen) \\
\hline Others & $\begin{array}{c}\text { Him (Ta), They(TaMen), Outers(WaiRen), Others(TaRen), } \\
\text { Another(BieRen) }\end{array}$ \\
\hline Aggressive & $\begin{array}{c}\text { Attack(Gongji), Fight(Fankang), War(ZhanŹheng), Confront(DuiKang), } \\
\text { Beat(XieJi) }\end{array}$ \\
\hline Non-aggressive & $\begin{array}{c}\text { Peace(HePing), Mild(WenHe),Trust(XinRen), Coorperation(HeZuo), } \\
\text { Friendly(YouShan) }\end{array}$ \\
\hline
\end{tabular}

Table 4 Steps and procedures in the IAT phase

\begin{tabular}{clccc}
\hline Step & \multicolumn{1}{c}{ Description } & $\begin{array}{c}\text { Response Key } \\
\text { D }\end{array}$ & $\begin{array}{c}\text { Response Key } \\
\text { K }\end{array}$ & Trials \\
\hline 1 & Target concept words (Practice) & Self & others & 20 \\
2 & Attribute concept words (Practice) & Attack & non-attack & 20 \\
3 & Compatibility joint task (Practice) & self+attack & others+non-attack & 20 \\
4 & Compatibility joint task (Test) & self+attack & others+non-attack & 40 \\
5 & Opposite target word discrimination & Others & Self & 20 \\
& (Practice) & & & \\
6 & Incompatibility joint task (Practice) & others+attack & self+non-attack & 20 \\
7 & Incompatibility joint task (Test) & others+attack & self+non-attack & 40 \\
\hline
\end{tabular}


corded as $300 \mathrm{~ms}$ when they were below $300 \mathrm{~ms}$, and recorded as $3000 \mathrm{~ms}$ when they were above $3000 \mathrm{~ms}$. All the reaction times were included regardless of whether they were correct or incorrect responses. The reaction times of the compatibility and incompatibility tasks were transformed into natural logarithms. The IAT effect index and its logarithm were calculated as the mean reaction time of the incompatibility task minus the mean of the compatibility task.

An independent-sample $t$-test showed no significant difference between the IAT effect of reaction times on the regulation group and the non-regulation group, $t(78)=-0.29, p>0.05$, and no significant difference on the IAT effect of logarithm, $t(78)=0.06, p>0.05$ (see Table 5).

\section{Discussion}

The results of Study 2 showed that the implicit bias toward aggression did not vary after the regulation of shame. After regulation using the self-blaming strategy, the IAT effect, representing the association between self and aggression, had a similar tendency as between the regulation and non-regulation conditions, indicating no regulation effect of shame on implicit aggression. The bias of self to aggressiveness was not affected by the regulation of shame.

The association between self and aggression in the IAT experiment refers to the implicit bias of self toward aggressiveness. In the process of socialization, individuals establish a psychological structure related to aggressive behavior, potentially affecting the individual's interpretation of environmental cues. The connection between the concept of self and the concept of aggression becomes a part of the connected network in the individual mind. Once the connection is stimulated, the self automatically activates and spreads, so that the individual's aggressive traits and behaviors can be automatically triggered, manifested as the individual's implicit aggression. Generally, implicit measures are thought to be more accurate, at least in the sense that they are less susceptible to socially desirable responding, faking, etc. Therefore, the implicit aggression is stable. Although implicit aggression could be influenced under some conditions (Dai et al., 2005; Xie et al., 2010; Yang, 2012), and one's implicit moral self is also affected by shame (Zhou, 2015), it is necessary to have a trigger to push the process and implement this change. The protective motive is one motivation of shame (de Hooge et al., 2010; de Hooge et al., 2018), and self-blaming strategy can possibly be a trigger. However, the effect size of self-blaming strategy may be small. Based on the content of the compatible and incompatible tasks in this experiment, the impact of self-blaming strategy is not enough to change the stable connection between the original self-concept and the aggressive concept. The IAT effect was similar between the two groups,

Table 5 Reaction times ( $m s$ ) and the IAT effect in different conditions

\begin{tabular}{lcccccc}
\hline Conditions & Index & Tasks & $M$ & SD & IAT effect & $t$ \\
\hline Non-regulation & Reaction times & Compatibility & 1077.33 & 227.47 & -78.44 & -0.29 \\
& & Incompatibility & 998.89 & 277.07 & & \\
Regulation & Reaction times & Compatibility & 1125.39 & 324.25 & -96.27 & \\
& & Incompatibility & 1029.12 & 304.97 & & \\
Non-regulation & \multirow{2}{*}{ Logarithm } & Compatibility & 6.9605 & 0.2121 & -0.0938 & 0.06 \\
& & Incompatibility & 6.8667 & 0.2981 & & \\
Regulation & \multirow{2}{*}{ Logarithm } & Compatibility & 6.9893 & 0.2682 & -0.0902 & \\
& & Incompatibility & 6.8991 & 0.2704 & & \\
\hline
\end{tabular}


indicating that the regulation using the selfblaming strategy could not change the association between "self" and "attack".

\section{General Discussion}

The findings of the two experiments in the current study showed the different effects of shame regulation on aggression, in which the selfregulation of shame through the self-blaming strategy enhanced adolescents' explicit aggression, but no effects existed involving implicit bias toward aggressiveness. This difference is related to the individual's perception of aggression.

Shame is closely related to aggression and it can induce aggression (Åslund et al., 2009; Heaven et al., 2009; Schoenleber et al., 2015). Anger and aggression are considered to be coping strategies to deal with shame (Elison et al., 2014). There exist restore and protective motivations following shame (de Hooge et al., 2010; de Hooge et al., 2018), corresponding to the confirmation or protection of self, respectively, depending on the triggers to motivation. Regarding self-regulation of shame, repressive coping serves as a protective function (Coifman et al., 2007), which is an effective response to a threat. Individuals experiencing repressive coping might not express it to the outside world, they maybe commit it to the internal ego, such as self-blaming. Specifically, self-blaming functions are a clue or trigger to activate protective motive of shame, leading to protective behavior, such as aggression. The results from Study 1 also confirmed indirectly some findings about the role of self-blaming. Self-blaming has a role in the relationship of shame and aggression (Zhang et al., 2013), and could affect individual's shame (Gao, 2016; Wang \& Sang, 2019). The self-blaming strategy is a defensive strategy (Sznycer et al., 2016) that can exacerbate injury to self-identity and self-worth of adolescents. Chinese traditional culture advocates the spirit of "cultivating self, family-discipline, governing the country and maintaining the world peace" (In Chinese, 修身, 齐家, 治国, 平天下) (Wang \& Sang, 2019), which describes the theory, principles and methods of moral cultivation by a number of Confucian and Neo-Confucian scholars. Chinese people pay more attention to self-cultivation and their own responsibilities for their behaviors, and they often regulate and manage their own affect and behavior using selfblaming strategy. If adolescents superimpose the extra effect of the self-blaming strategy on the original relationship between shame and aggression, they begin to do self-defense and resistance, and then subjective aggression becomes a major channel for venting; therefore, the immediate effect of shame leads to the increased explicit aggression among adolescents who have experienced shameful situations.

However, adolescents do not clearly perceive their own aggressiveness when they process some concepts on the IAT test. Individuals are accustomed to the cognitive attribution of shameful events under their own attribution styles. Based on the cognitive attribution theory of self-conscious emotions (Lewis, 2008), when the self-blaming strategy is used to deal with a shameful event, adolescents attribute the individual's feelings of shame to themselves. But, the relationship between shame and implicit aggression is steady and becomes one part of personality traits. And, as far as implicit cognitive and social behavior is concerned, the protective motive in self-blaming strategy is not enough to affect the implicit aggression. Therefore, the association between shame and implicit aggressiveness is hard to change by self-blaming strategy.

There are some issues to address. The first involves the measurement of aggression. The tool developed by Buss and Perry (1992) is designed mainly to evaluate a trait aggression rather than state hostility or aggressive behavior. There exists a strong relationship between trait and state sociality. And the responses to these items of questionnaire could also reflect the attitudes in the moment. It would be better to measure directly the acute tendency towards aggressive behavior in future research. IAT is often applied to measure strength of association between aggressive tendencies and outwards expression (Richetin 
\& Richardson, 2008; Xie et al., 2010; Yang, 2012). One study found priming shame could negatively affect an individual's implicit moral self (Zhou, 2015). According to IAT procedure (Greenwald et al., 2003), there are practice tasks taken before test tasks. The time for practice tasks potentially diminishes the emotional response during test tasks, even though it is very short. Therefore, future studies should use a method more accurate than IAT, in order to evaluate implicit aggression. The second issue is about individual dispositions in the design. Some researchers have found that different kinds of narcissism, such as over/covert, grandiose/vulnerable, are related to different behaviors (Derry, Ohan, \& Bayliss, 2019; Fossati, Borroni, Eisenberg, \& Maffei, 2010; Martinez, Zeichner, Reidy, \& Miller, 2008). Besides gender, other individual traits, such as narcissism, could be taken into consideration in future research.

\section{Ethics Statement}

This study was carried out in accordance with the recommendations of Nantong University Committee with written informed consent from all subjects. All subjects gave written informed consent in accordance with the Declaration of Helsinki. The protocol was approved by Nantong University Committee.

\section{Acknowledgement}

This study was funded by The Key Project of Philosophy and Social Science Research in Colleges and Universities in Jiangsu Province (No. 2017ZDIXM134) and National Natural Science Foundation of China (No. 31371043).

\section{References}

Åslund, C., Leppert, J., Starrin, B., \& Nilsson, K. W. (2009). Subjective social status and shaming experiences in relation to adolescent depression. Archives of Pediatrics \& Adolescent Medicine, 163(1), 55-60. doi: 10.1001/archpedi.163.1.55

Berkowitz, L. (2012). A different view of anger: The cognitive-neoassociation conception of the rela- tion of anger to aggression. Aggressive Behavior, 38(4), 322-333. doi: 10.1002/ab.21432

Buss, A. H., \& Perry, M. (1992). The aggression questionnaire. Journal of Personality and Social Psychology, 63(3), 452-459.

Cándea, D.-M., \& Szentágotai-Tătar, A. (2018). The impact of self-compassion on shame-proneness in social anxiety. Mindfulness, 9(6), 1816-1824. doi: 10.1007/s12671-018-0924-1

Coifman, K. G., Bonanno, G. A., Ray, R. D., \& Gross, J. J. (2007). Does repressive coping promote resilience? Affective-autonomic response discrepancy during bereavement. Journal of Personality and Social Psychology, 92(4), 745-758. doi: 10. 1037/0022-3514.92.4.745

Dai, Y., Wang, M., \& Qian, M. (2012). Research and theory about shame and PTSD (in Chinese). Chinese Journal of Clinical Psychology, 20(2), 190193. http://clinicalpsychojournal.yywkt.cn/Magazine/Show.aspx?ID=138982

Dai, C., Yang, Z., \& Wu, M. (2005). An experimental research on implicit aggression (in Chinese). Psychological Science, 28(1), 96-98. http:// www.cqvip.com/Main/Detail.aspx?id=12138401

de Hooge, I. E., Breugelmans, S. M., Wagemans, F. M. A., \& Zeelenberg, M. (2018). The social side of shame approach versus withdrawal. Cognition \& Emotion, 32(8), 1671-1677. doi: 10.1080/ 02699931.2017 .1422696

de Hooge, I. E., Zeelenberg, M., \& Breugelmans, S. M. (2010). Restore and protect motivations following shame. Cognition \& Emotion, 24(1), 111127. doi: $10.1080 / 02699930802584466$

Deng, X., Sang, B., \& Luan, Z. (2013). Up- and downregulation of daily emotion: An experience sampling study of Chinese adolescents' regulatory tendency and effects. Psychological Reports, 113(2), 552-565. doi: 10.2466/09.10.PR0. $113 \times 22 z 4$

Derry, K. L., Ohan, J. L., \& Bayliss, D. M. (2019). Fearing failure: Grandiose narcissism, vulnerable narcissism, and emotional reactivity in children. Child Development. doi: 10.1111/ cdev. 13264

Eisenberger, N. I. (2011). Why rejection hurts: What social neuroscience has revealed about the brain's response to social rejection. In J. C. J. Decety (Ed.), The Handbook of Social Neuroscience (pp. 586-598). New York: Oxford University Press.

Eisenberger, N. I., Lieberman, M. D., \& Williams, K. D. (2003). Does rejection hurt? An fMRI study of social exclusion. Science, 302(5643), 290-292. doi: 10.1126/science.1089134

Elison, J., Garofalo, C., \& Velotti, P. (2014). Shame and aggression: Theoretical considerations. Ag- 
gression and Violent Behavior, 19(4), 447-453. doi: 10.1016/j.avb.2014.05.002

Elison, J., Lennon, R., \& Pulos, S. (2006). Investigating the compass of shame: The development of the Compass of Shame Scale. Social Behavior and Personality, 34(3), 221-238. doi: 10.2224/ sbp.2006.34.3.221

Fan, Z., \& Yu, G. (2008). A study on the relationship of self-esteem and attributional style with guilt and shame (in Chinese). Psychology Exploration, 28(4), 57-61. http://pe.paperonce.org/oa/DArticle. aspx? type=view\&id=200804013

Fossati, A., Borroni, S., Eisenberg, N., \& Maffei, C. (2010). Relations of proactive and reactive dimensions of aggression to overt and covert narcissism in nonclinical adolescents. Aggressive Behavior, 36(1), 21-27. doi: 10.1002/ab.20332

Gao, J. (2016). Emotion regulation of shame (in Chinese). Beijing: Intellectual Property Publishing House.

Gao, J., Qian, M., \& Wang, W. (2011). Cognitive emotion regulation of shame and general negative emotions (in Chinese). Chinese Journal of Clinical Psychology, 19(6), 807-809. http:// clinicalpsychojournal.yywkt.cn/Magazine/ Show.aspx?ID=139840

Gao, J., Zhao, Q., Wang, M., Dai, Y., \& Qian, M. (2012). Selection of cognitive emotion regulation strategy on shame: Impact of self-appraisals (in Chinese). Chinese Journal of Clinical Psychology, 20(4), 469-473. http://clinicalpsychojournal.yywkt.cn/ Magazine/Show.aspx?ID=139187

Garnefski, N., \& Kraaij, V. (2007). The cognitive emotion regulation questionnaire: Psychometric features and prospective relationships with depression and anxiety in adults. European Journal of Psychological Assessment, 2007, 23(3), 141-149. doi: 10.1027/1015-5759.23.3.141

Gold, J., Sullivan, M. W., \& Lewis, M. (2011). The relation between abuse and violent delinquency: The conversion of shame to blame in juvenile offenders. Child Abuse \& Neglect, 35(7), 459-467. doi:10.1016/j.chiabu.2011.02.007

Greenwald, A. G., Nosek, B., \& Banaji, M. (2003). Understanding and using the implicit association test: I. An improved scoring algorithm. Journal of Personality and Social Psychology, 85(2), 197216. doi: 10.1037/0022-3514.85.2.197

Gross, J. J. (1998). Antecedent- and response-focused emotion regulation: Divergent consequences for experience, expression, and physiology. Journal of Personality and Social Psychology, 74(1), 224-237.

Gross, J. J. (2002). Emotion regulation: Affective, cognitive, and social consequences. Psycho- physiology, 39, 281-291. doi: 10.1017 . S0048577201393198

Gross, J. J. (2015). The Extended Process Model of Emotion Regulation: Elaborations, applications, and future directions. Psychological Inquiry, 26(1), 130-137. doi: 10.1080/1047840X.2015.989751

Gross, J. J., \& Levenson, R. W. (1993). Emotional suppression: Physiology, self-report, and expressive behavior. Journal of Personality and Social Psychology, 64(6), 970-986. doi: 10.1037/00223514.64.6.970

Gross, J. J., \& Thompson, R. A. (2007). Emotion regulation: Conceptual foundations. In J. J. Gross (Ed.), Handbook of Emotion Regulation (pp. 3-24). New York, NY: Guilford.

Haga, S. M., Kraft, P., \& Corby, E-K. (2009). Emotion regulation: Antecedents and well-being outcomes of cognitive reappraisal and expressive suppression in cross-cultural samples. Journal of Happiness Studies, 10(3), 271-291. doi: 10.1007/ s10902-007-9080-3

Harper, F. W. K., \& Arias, I. (2004). The role of shame in predicting adult anger and depressive symptoms among victims of child psychological maltreatment. Journal of Family Violence, 19(6), 359367. doi: 10.1007/s10896-004-0681-x

Heaven, P. C. L., Ciarrochi, J., \& Leeson, P. (2009) The longitudinal links between shame and increasing hostility during adolescence. Personality and Individual Differences, 47(8), 841-844. doi: 10.1016/j.paid.2009.07.002

Hunger, I., \& Böhlke, N. (2018). On the boundaries of shame. A qualitative study of situations of overstepping boundaries (of shame) in physical education as seen from the students' perspective. Forum Qualitative Sozialforschung / Forum: Qualitative Social Research, 18(2), Art. 2. doi: 10.17169/fqs-18.2.2623

Liu, J., Zhou, Y., \& Gu, W. (2009). Reliability and validity of Chinese version of Buss-Perry Aggression Questionnaire in adolescents (in Chinese). Chinese Journal of Clinical Psychology, 17(4) 449-451. http://clinicalpsychojournal.yywkt.cn/ Magazine/Show.aspx?ID=140074

Lewis, H. B. (1971). Shame and guilt in neurosis New York: International Universities Press.

Lewis, M. (2008). Self-conscious emotions: Embarrassment, pride, shame, and guilt. In M. Lewis, J. M. Haviland-Jones, \& L. F. Barrett (Eds.), Handbook of Emotions (pp. 742-756). New York: Guilford Press.

Martinez, M. A., Zeichner, A., Reidy, D. E., \& Miller, J. D. (2008). Narcissism and displaced aggression: Effects of positive, negative, and delayed feedback. Personality and Individual Differ- 
ences, 44(1), 140-149. doi: 10.1016/j.paid. 2007.07.012

McRae, K., Ciesielski, B., \& Gross, J. J. (2012). Unpacking cognitive reappraisal: Goals, tactics, and outcomes. Emotion, 12(2), 250-255. doi: 10.1037/ a0026351

Monroe, A. (2008). Shame solutions: How shame impacts school-aged children and what teachers can do to help. The Educational Forum, 73(1), 58-66. doi: 10.1080/00131720802539614

Nathanson, D. L. (1992). Shame and pride: Affect, sex, and the birth of the self. New York: W. W. Norton \& Company.

Richetin, J., \& Richardson, D. S. (2008). Automatic processes and individual differences in aggressive behavior. Aggression and Violent Behavior 13(6), 423-430. doi: 10.1016/j.avb.2008.06.005

Schalkwijk, F., Stams, G. J., Stegge, H., Dekker, J., \& Peen, J. (2016). The conscience as a regulatory function: Empathy, shame, pride, guilt, and mora orientation in delinquent adolescents. International Journal of Offender Therapy and Comparative Criminology, 60(6), 675-693. doi: 10.1177/ $0306624 X 14561830$

Scheff, T. (2012). A social/emotional theory of "mental illness". International Journal of Social Psychiatry, 59(1), 87-92. doi: 10.1177| 0020764012445004

Scheff, T. (2014). The ubiquity of hidden shame in modernity. Cultural Sociology, 8(2), 129-141. doi: 10.1177/1749975513507244

Scheff, T., \& Retzinger, S. M. (1997). Shame, anger and the social bond: A theory of sexual offenders and treatment. Electronic Journal of Sociology, 3(1). https://www.sociology.org/ejs-archives/ vol003.001/sheff.html

Schoenleber, M., Sippel, L. M., Jakupcak, M., \& Tull, M. T. (2015). Role of trait shame in the association between posttraumatic stress and aggression among men with a history of interpersonal trauma. Psychological Trauma: Theory, Research, Practice, and Policy, 7(1), 43-49. doi: 10.1037/ a0037434

Sinha, M. (2017). Shame and psychotherapy: Theory, method and practice. In E. Vanderheiden \& C.-H Mayer (Eds.), The value of shame (pp. 251-275) Cham, Switzerland: Springer International Publishing.

Smetana, J. G. (2002). Culture, autonomy, and personal jurisdiction in adolescent-parent relationships. In H. W. Reese \& R. Kail (Eds.), Advances in Child Development and Behavior (Vol. 29). Orlando, Florida: Academic Press.

Smetana, J., Crean, H. F., Campione-Barr, N. (2005) Adolescents' and parents' changing conceptions of parental authority. New Directions for Child and Adolescent Development, 2005(108), 31-46. doi: $10.1002 / \mathrm{cd} .126$

Steinberg, L. (2017). Adolescence. New York: McGraw-Hill.

Stuewig, J., \& Tangney, J. P. (2007). Shame and guilt in antisocial and risky behaviors. In J. L. Tracy, R. W. Robins, \& J. P. Tangney (Eds.), The Self-conscious emotions: Theory and research (pp. 371388). New York: Guilford Press.

Stuewig, J., Tangney, J. P., Heigel, C., Harty, L., \& McCloskey, L. (2010). Shaming, blaming, and maiming: Functional links among the moral emotions, externalization of blame, and aggression. Journal of Research in Personality, 44(1), 91-102. doi: 10.1016/j.jp. 2009.12.005

Stuewig, J., Tangney, J. P., Kendall, S., Folk, J. B., Meyer, C. R., \& Dearing, R. L. (2015). Children's proneness to shame and guilt predict risky and illegal behaviors in young adulthood. Child Psychiatry \& Human Development, 46(2), 217-227. doi: $10.1007 / \mathrm{s} 10578-014-0467-1$

Sznycer, D., Tooby, J., Cosmides, L., Porat, R., Shalvi, S., \& Halperin, E. (2016). Shame closely tracks the threat of devaluation by others, even across cultures. Proceedings of the National Academy of Sciences, 113(10), 2625-2630. doi:10.1073/ pnas. 1514699113

Tangney, J. P. (1992). Situational determinants of shame and guilt in young adulthood. Personality and Social Psychology Bulletin, 18(2), 199-206. doi:10.1177/0146167292182011

Van Vliet, K. J. (2008). Shame and resilience in adulthood: A grounded theory study. Journal of Counseling Psychology, 55(2), 233-245. doi: 10.1037/ 0022-0167.55.2.233

Velotti, P., Garofalo, C., Bottazzi, F., \& Caretti, V. (2016). Faces of shame: Implications for self-esteem, emotion regulation, aggression, and wellbeing. The Journal of Psychology, 151(2), 171184. doi: $10.1080 / 00223980.2016 .1248809$

Wang, L. (2017). Emotion regulation of shame for adolescents (in Chinese). Shanghai: East China Normal University.

Wang, L., \& Sang, B. (2019). The effect of regulation on shame in adolescence in China. In $E$. Vanderheiden \& C.-H. Mayer (Eds.), The bright side of shame (pp. 67-75). Cham, Switzerland: Springer International Publishing. doi: 10.1007/9783-030-13409-9 5

Xie, X., Bi, Y. \& Luo, Y. (2010). Effects of situational positive clues on implicit aggression (in Chinese). Psychological Science, 33(1), 44-47.

Yang, W. (2012). The comparative research of the influence of the scene clues to the athletes' im- 
plicit offensive (in Chinese). Changsha: Hunan Normal University.

Zhou, S. (2015). Implicit assessment of moral selfevaluation in shame-proneness (in Chinese). Chongqing: Southwest University.

Zhou, Y. (2007). The influencing factors and its mechanism of implicit aggression (in Chinese). Shanghai: East China Normal University.

Zhu, R., Xu, Z., Tang, H., Liu, J., Wang, H., An, Y., Mai, X., \& Liu, C. (2019). The effect of shame on anger at others: Awareness of the emotioncausing events matters. Cognition \& Emotion, 33(4), 696-708. doi: 10.1080/02699931.2018. 1489782

Zhang, F., Zhang, D., \& Huang, X. (2013). The relationship between junior students' shame-proneness and aggression: The mediating role of shame coping (in Chinese). $16^{\text {th }}$ Congress of Psychology of China. 